\title{
Effectiveness of Balloon Valvuloplasty in the Young Adult With Congenital Aortic Stenosis
}

\author{
Satinder K. Sandhu, MB, BS, Thomas R. Lloyd, MD, Dennis C. Crowley, MD, and \\ Robert H. Beekman, MD
}

\begin{abstract}
The objective of this study was to assess the effectiveness of balloon valvuloplasty in the young adult with congenital aortic stenosis and to compare its effectiveness with children. Percutaneous balloon valvuloplasty is effective in children with congenital aortic stenosis, but not in adults with acquired calcific aortic stenosis. Because effectiveness of balloon valvuloplasty in young adults with congenital aortic stenosis is not well defined, we evaluated the outcome in 15 patients aged $16-24$ years $(18 \pm 0.6$; mean \pm SEM) who underwent balloon valvuloplasty from 1985 to 1993 . The aortic valve annulus diameter ranged from 18.5 to $30 \mathrm{~mm}(24 \pm 0.9)$. The aortic valve was bicuspid in 12 and tricuspid in 3 patients, and calcification was present in one patient. Balloon valvuloplasty was performed using a double balloon technique in 12 patients and a single balloon technique in three patients. Three patients had inadequate relief of gradient with a residual peak systolic gradient $\geq 70 \mathrm{~mm} \mathbf{H g}$. Three patients required valve replacement-two patients for a residual gradient $\geq 70 \mathrm{mg} \mathrm{Hg}$, and one patient 4 years later for severe aortic valve regurgitation. Eight of the remaining 12 have undergone elective follow-up catheterization 1.2-2.5 years $(1.5 \pm 0.1)$ later. The peak systolic aortlc valve gradient decreased by $55 \%$ from $73 \pm 5.8 \mathrm{~mm} \mathrm{Hg}$ to $35 \pm 5.4 \mathrm{~mm} \mathrm{Hg}$ immediately postvalvuloplasty, and was 30 $\pm 4.4 \mathrm{~mm} \mathrm{Hg}$ at follow-up $(P<0.001)$. The left ventricular systolic pressure decreased from $179 \pm 7.5$ to $147 \pm 6.5 \mathrm{~mm} \mathrm{Hg}$ immediately postvalvuloplasty and was $147 \pm 4 \mathrm{~mm}$ $\mathrm{Hg}$ at follow-up. Aortic insufficiency was unchanged after valvuloplasty in 9 , increased by $1+$ in 4 , and by $2+$ in 2 patients. Balloon valvuloplasty was as effective in these young adults as in 70 children (age $6 \pm 0.7$ years) with congenital aortic stenosis (peak systolic gradient pre- $79 \pm 3 \mathrm{~mm} \mathrm{Hg}$ versus post- $34 \pm 2 \mathrm{mg} \mathrm{Hg}$; at 1-2 years follow-up $34 \pm 4 \mathrm{~mm}$ $\mathrm{Hg}$ ).

Balloon valvuloplasty provides effective treatment in most young adults with congenital aortic stenosis, without early restenosis. Balloon valvuloplasty is as effective in young adults as in children, where it is currently the treatment of choice. (c) 1995 Wiley-Liss, Inc.
\end{abstract}

Key words: balloon aortic valvuloplasty, young adult, children, aortic insufficiency

\section{INTRODUCTION}

Data from the adult literature suggest that percutaneous balloon valvuloplasty is of little benefit to adults with acquired calcific aortic stenosis, and that aortic valve replacement is the procedure of choice for this condition [1-4]. This is in marked contrast to the experience in children with congenital aortic stenosis where balloon valvuloplasty is very effective in reducing the peak systolic gradient, with little or no early restenosis [5-9]. The question arises whether balloon valvuloplasty is of benefit to adult patients with congenital aortic valve stenosis.

The purpose of this report is to describe our experience with percutaneous balloon valvuloplasty for congenital aortic valve stenosis in patients 16 years of age and older. In most cases, aortic balloon valvuloplasty provided significant acute reduction in the peak systolic gra- dient; short-term follow-up data document lasting relief of stenosis in most patients. A second objective of this study is to compare these results with those in patients younger than 16 years of age, a group in whom balloon valvuloplasty is clearly efficacious [5-9].

From the Department of Pediatrics, Division of Pediatric Cardiology, C.S. Mott Children's Hospital, University of Michigan Medical Center, Ann Arbor, Michigan.

Received November 7, 1994; revision accepted February 27, 1995.

Address reprint requests to Satinder K. Sandhu, Department of Pediatrics, Division of Pediatric Cardiology, Oregon Health Sciences University, 3181 S.W. Sam Jackson Park Road, Portland, OR 97201 3098 .

Presented, in part, at the 66th Scientific Sessions, American Heart Association meetings, November 8-11, 1993, Atlanta, GA. 


\section{METHODS}

The study group consists of all patients 16 years or older with congenital aortic stenosis who underwent balloon valvuloplasty at our institution between 1985 and 1993. Indications for balloon valvuloplasty included a peak systolic aortic valve gradient of $\geq 70 \mathrm{~mm} \mathrm{Hg}$ or $\geq 50 \mathrm{~mm} \mathrm{Hg}$ in association with symptoms or ischemic changes on electrocardiogram. All patients had a transthoracic 2-D echocardiogram before and after balloon valvuloplasty. The aortic valve anatomy was defined as bicuspid or tricuspid. In addition the presence or absence of calcification was assessed on echocardiogram by the presence of an echo bright aortic valve leaflet. Informed consent for balloon valvuloplasty was obtained; Institutional Review Board approval was also obtained for cases performed prior to 1989 .

\section{Valvuloplasty Procedure}

A complete right and left heart hemodynamic study was performed under light sedation. The peak systolic pressure gradient was measured from simultaneously obtained left ventricular and aortic pressure tracings. Cardiac output was measured in triplicate before and after balloon valvuloplasty. An aortogram was obtained to assess the degree of aortic insufficiency before and after valvuloplasty [10]. The aortic valve annulus was measured from the left ventricular angiogram, using a calibrated marker catheter.

Balloon valvuloplasty was performed as previously described [5,6]. In three patients, a single balloon technique was used; in 12 cases, a double balloon technique was used (Fig. 1). The balloon/annulus diameter ratio was $0.96 \pm 0.08$ in the single balloon and $1.3 \pm 0.1$ in the double balloon population. The balloon was inflated by hand two to four times with minor adjustments in position to assure that the balloon was properly positioned across the valve. The balloon angioplasty catheter was then exchanged for a pigtail catheter and repeat hemodynamic and angiographic data obtained.

\section{Follow-up Study}

An elective follow-up cardiac catheterization was obtained 1-3 years after valvuloplasty in 8 of the 15 patients. The peak systolic pressure gradient was measured across the left ventricular outflow tract from simultaneous left ventricular and ascending aorta pressure measurements. Cardiac output was obtained by the thermodilution technique in triplicate, and cineangiograms were performed in the left ventricle and the aorta. Follow-up 2-D echocardiogram and Doppler studies were performed in all patients.

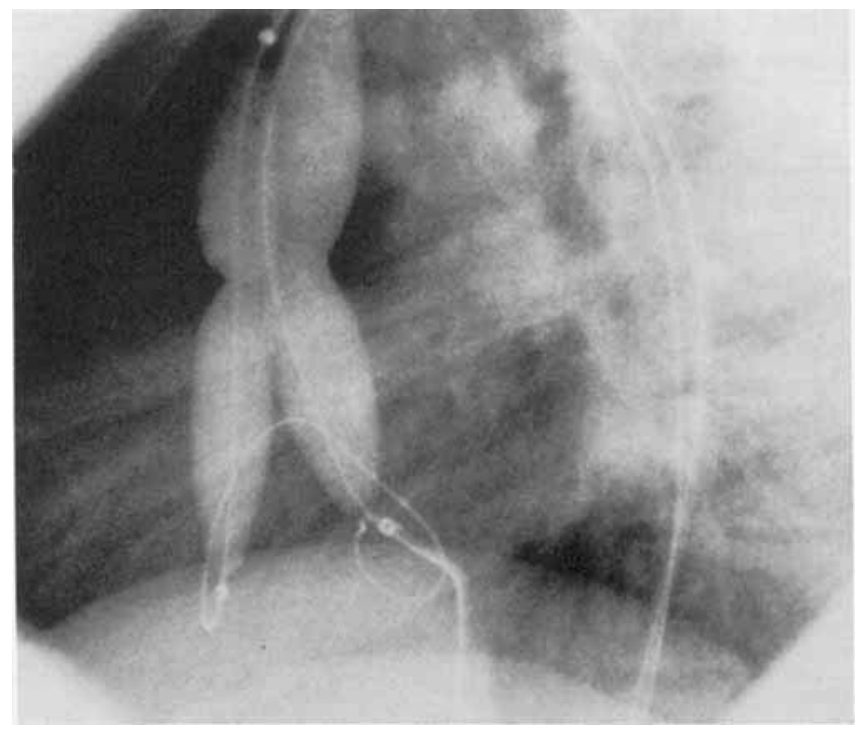

Fig. 1. Double balloon aortic valvuloplasty in an 18-year-old with severe congenital aortic stenosis (case 13). Because only one femoral artery was patent, one catheter was placed retrograde and one antegrade via a transeptal puncture.

\section{Data Analysis}

Data are presented as mean values \pm SEM. Values obtained before and immediately after valvuloplasty and at follow-up are compared with repeated measures analysis of variance. A $P$-value of $<0.05$ is required as evidence of statistical significance between measurements.

\section{RESULTS \\ Study Patients}

Fifteen patients aged 16 years and older underwent balloon valvuloplasty for congenital aortic stenosis between 1985 and 1993 at our institution. At valvuloplasty these young adults ranged in age from 16 to 24 years (18 \pm 0.6 years) and in weight from 49 to $120 \mathrm{~kg}(71.2 \pm$ $4.5 \mathrm{~kg}$ ). Seven patients had undergone a surgical aortic valvotomy $2-11$ years (median $=9.9$ years) prior to balloon valvuloplasty but had evidence of postoperative restenosis [6]. One had also undergone resection of a subaortic membrane. Another had undergone an attempted balloon valvuloplasty at another institution 2 months prior to this procedure.

All patients had congenital valvar aortic stenosis. The aortic valve annulus diameter ranged from 18.5 to 30 $\mathrm{mm}(24 \pm 0.9 \mathrm{~mm})$. In 12 patients, the aortic valve was bicuspid, and in three it was tricuspid. Mild aortic valve calcification was present in one patient. One patient had Noonan's syndrome with a thickened dysplastic aortic valve. Before valvuloplasty, the peak systolic aortic 
TABLE I. Clinical and Hemodynamic Data from 15 Young Adults With Congenital Aortic Stenosis Undergoing Balloon Valvuloplasty

\begin{tabular}{|c|c|c|c|c|c|c|c|c|c|c|c|c|c|c|c|c|c|c|c|c|}
\hline \multirow[b]{2}{*}{ Case } & \multirow{2}{*}{$\begin{array}{l}\text { Age } \\
(\mathrm{yr})\end{array}$} & \multirow{2}{*}{$\begin{array}{c}\text { Wt } \\
(\mathbf{k g})\end{array}$} & \multirow{2}{*}{$\begin{array}{l}\text { Valve } \\
\text { morph }\end{array}$} & \multirow{2}{*}{$\begin{array}{c}\text { Annulus } \\
(\mathrm{mm})\end{array}$} & \multirow{2}{*}{$\begin{array}{c}\text { Balloon } \\
\text { (mm) }\end{array}$} & \multicolumn{3}{|c|}{ Gradient (mm Hg) } & \multicolumn{3}{|c|}{ LVS (mm $\mathrm{Hg})$} & \multicolumn{3}{|c|}{ LVEDP $(\mathrm{mm} \mathrm{Hg})$} & \multicolumn{3}{|c|}{ CI $\mathrm{L} / \mathrm{min} / \mathrm{m}^{2}$} & \multicolumn{3}{|c|}{ AI $(0-4+)$} \\
\hline & & & & & & Pre & Post & $\mathrm{f} / \mathrm{u}$ & Pre & Post & $\mathbf{f} / \mathbf{u}$ & Pre & Post & $\mathbf{f} / \mathbf{u}$ & Pre & Post & $\mathrm{f} / \mathrm{u}$ & Pre & Post & $f / u$ \\
\hline 1 & 16 & 64 & Bicuspid & 23 & 20 & 70 & 41 & 48 & 182 & 161 & 148 & 18 & 16 & 16 & 2.9 & 2.6 & 2.6 & $0+$ & $1+$ & $0+$ \\
\hline 2 & 16 & 49 & Bicuspid & 19 & 20 & 110 & 70 & - & 200 & 200 & - & 18 & 9 & - & 4.1 & 4.0 & - & $0+$ & $0+$ & - \\
\hline 3 & 16 & 53 & Bicuspid & 19 & 20 & 76 & 46 & - & 186 & 146 & - & 15 & 6 & - & 3.7 & 3.1 & - & $1+$ & $1+$ & - \\
\hline 4 & 16 & 59 & Tricuspid & 19 & $15+12$ & 60 & 18 & 20 & 160 & 121 & 135 & 18 & 8 & 20 & 3.2 & 2.9 & 3.4 & $2+$ & $2+$ & $1+$ \\
\hline 5 & 16 & 78 & Bicuspid & 25 & $15+18$ & 67 & 13 & 27 & 172 & 142 & 165 & 20 & 26 & 18 & 3.4 & 3.5 & 3.4 & $0+$ & $2+$ & $2+$ \\
\hline 6 & 21 & 75 & Bicuspid & 30 & $18+18$ & 56 & 14 & 10 & 160 & 124 & 140 & 12 & 22 & 23 & 2.6 & & 2.8 & $1+$ & $3+$ & $3+$ \\
\hline 7 & 17.8 & 94 & Bicuspid & 30 & $20+20$ & 51 & 20 & 20 & 156 & 142 & 132 & 13 & 10 & 8 & 4.3 & & 3.4 & $1+$ & $1+$ & $0+$ \\
\hline 8 & 20 & 75 & Tricuspid & 23 & $15+15$ & 73 & 26 & 35 & 188 & 134 & 145 & 8 & 4 & 15 & 2.7 & 2.3 & 5.9 & $1+$ & $1+$ & $1+$ \\
\hline 9 & 17 & 65 & Bicuspid & 25 & $15+15$ & 69 & 32 & 36 & 179 & 127 & 150 & 16 & 8 & 15 & 3.2 & 3.2 & 3.4 & $1+$ & $1+$ & $1+$ \\
\hline 10 & 20 & 66 & Tricuspid & 27 & $18+15$ & 58 & 29 & 40 & 130 & 110 & 160 & 6 & 8 & 10 & 2.3 & 2.2 & 2.9 & $2+$ & $3+$ & $3+$ \\
\hline 11 & 18 & 79 & Bicuspid & 24 & $15+18$ & 75 & 40 & - & 180 & 145 & - & 13 & 6 & - & 5.8 & 4.3 & - & $1+$ & $1+$ & - \\
\hline 12 & 23.9 & 61 & Bicuspid & 18.5 & $15+12$ & 100 & 70 & - & 210 & 170 & - & 14 & 16 & - & 2.5 & 2.7 & - & $2+$ & $3+$ & - \\
\hline 13 & 18 & 120 & Bicuspid & 25 & $18+15$ & 128 & 70 & - & 258 & 192 & $\ldots$ & 11 & 10 & - & 4.2 & 3.9 & - & $2+$ & $2+$ & - \\
\hline 14 & 17 & 66 & Bicuspid & 22.5 & $15+12$ & 60 & 15 & - & 170 & 140 & - & 12 & 11 & - & 2.8 & - & - & $3+$ & $3+$ & - \\
\hline 15 & 17 & 64 & Bicuspid & 25 & $15+15$ & 50 & 20 & - & 160 & 150 & - & 15 & 11 & - & 2.8 & - & - & $1+$ & $2+$ & 一 \\
\hline Mean & 18 & 71 & - & 24 & 一 & 73 & 35 & 30 & 179 & 147 & 147 & 14 & 11 & 15.6 & 3.4 & 3.2 & 3.5 & & & \\
\hline SE & 0.6 & 4.5 & - & 0.9 & - & 5.8 & 5.4 & 4.4 & 7.5 & 6.5 & 4 & 1 & 1.6 & 1.7 & 0.2 & 0.2 & 0.4 & & & \\
\hline$P$-value* & - & - & - & - & - & - & $<0.001$ & $<0.001$ & - & $<0.001$ & 0.04 & - & 0.112 & 0.385 & - & 0.056 & 0.383 & & & \\
\hline
\end{tabular}

*Compared to pre-balloon valvuloplasty. Mean $\pm S E$.

AI, aortic insufficiency; $\mathrm{Cl}$, cardiac index; f/u, follow-up cath 1-3 years after valvuloplasty; LVEDP, left ventricular end diastolic pressure; LVS, left ventricular systolic pressure; Morph, morphology; Post, immediately after valvuloplasty; Pre, immediately before valvuloplasty; Wt, weight.

valve gradient was $73 \pm 5.8 \mathrm{~mm} \mathrm{Hg}(50-128 \mathrm{~mm} \mathrm{Hg})$, the left ventricular systolic pressure was $179 \pm 7.5 \mathrm{~mm}$ $\mathrm{Hg}$ (130-258 $\mathrm{mm} \mathrm{Hg})$, and the left ventricular end-diastolic pressure was $14 \pm 1 \mathrm{~mm} \mathrm{Hg}(6-20 \mathrm{~mm}$ $\mathrm{Hg}$ ). Aortic valve insufficiency was absent in three, graded as $1+$ in seven, $2+$ in four, and $3+$ in one patient (on a $0-4+$ scale). The cardiac index was normal $\left(3.4 \pm 0.2 \mathrm{~L} / \mathrm{min} / \mathrm{m}^{2}\right)$. Aortic valve area was not calculated because of the presence of aortic regurgitation in most patients.

\section{Acute Effects of Balloon Valvuloplasty}

The acute effects of balloon valvuloplasty are summarized in Table I. The peak systolic aortic valve gradient was reduced acutely by $55 \%$, from $73 \pm 5.8$ to $35 \pm 5.4 \mathrm{~mm} \mathrm{Hg}(P<0.001)$. The left ventricular systolic pressure decreased from $179 \pm 7.5$ to $147 \pm$ $6.5 \mathrm{~mm} \mathrm{Hg}(P<0.001)$. There was a trend for the left ventricular end-diastolic pressure to decrease which did not show statistical significance $(14 \pm 1$ to $11 \pm 1.6$ $\mathrm{mm} \mathrm{Hg}, P=0.11)$. The heart rate and cardiac index were unchanged. The degree of gradient reduction was similar in patients with and without a prior surgical valvotomy.

After valvuloplasty, aortic valve insufficiency was unchanged in nine patients. Four had a $1+$ increase in aortic valve insufficiency, and two had a $2+$ increase in aortic valve insufficiency. No patient had greater than a $2+$ increase in aortic valve insufficiency (Fig. 2). There was no death, stroke, hemorrhage or loss of pulses after balloon valvuloplasty.

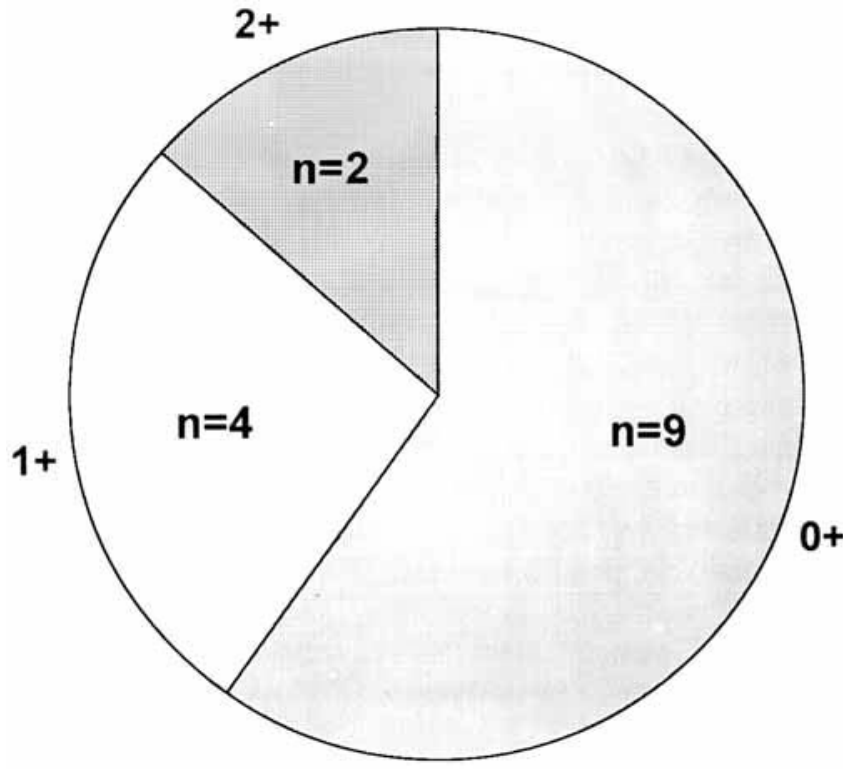

Fig. 2. Increase in aortic insufficiency immediately after balloon valvuloplasty, as documented by aortography.

\section{Follow-up Data}

Two patients with inadequate gradient relief (residual gradient $\geq 70 \mathrm{~mm} \mathrm{Hg}$ ) underwent aortic valve replacement shortly after balloon valvuloplasty. A 16-year-old boy with Noonan's syndrome (case 2, Table I) underwent aortic valve replacement and at surgery as noted to have a dysplastic valve with a hypoplastic annulus (aortic valve annulus diameter $19 \mathrm{~mm}$ ). The 
second patient was an 18-year-old boy (case 13, Table I) who had undergone a prior surgical valvotomy and a balloon valvuloplasty at another institution. Valvuloplasty resulted in an acute decrease in gradient from 128 $\mathrm{mm} \mathrm{Hg}$ to $70 \mathrm{~mm} \mathrm{Hg}$ which was thought inadequate and he subsequently underwent aortic valve replacement.

Eight of the remaining 13 patients have had an elective follow-up cardiac catheterization 1.2 to 2.5 years ( $1.5 \pm$ 0.3 years) after balloon aortic valvuloplasty. At follow-up catheterization, the peak systolic pressure gradient (Fig. 3 ) remained significantly reduced from that prior to valvuloplasty $(30 \pm 4.4$ versus $73 \pm 5.8 \mathrm{~mm} \mathrm{Hg}, P<0.001)$.

There was no restenosis over this follow-up period, as the aortic valve gradient at follow-up had decreased slightly from that immediately post-valvuloplasty ( $35 \pm$ 5.4 versus $30 \pm 4.4 \mathrm{~mm} \mathrm{Hg}, P=0.04$ ). The left ventricular systolic pressure also remained decreased (179 \pm 7.5 to $147 \pm 4 \mathrm{~mm} \mathrm{Hg}, P=0.04)$, and had not changed from that post valvuloplasty $(147 \pm 6.5$ vs $147 \pm 4 \mathrm{~mm}$ $\mathrm{Hg}$ ). The left ventricular end-diastolic pressure at follow-up $(15.6 \pm 1.7 \mathrm{~mm} \mathrm{Hg})$ was not significantly different from that measured before or immediately after valvuloplasty. The degree of aortic valve insufficiency documented by follow-up cardiac catheterization had decreased by a grade of $1+$ in three patients and was stable in six patients, compared to the degree of valve insufficiency documented immediately after valvuloplasty. No patient had an increase in aortic regurgitation at followup. A 21-year-old man (case 6, Table 1) had an acute increase in aortic regurgitation from 1 to $3+$ and an increase in LVEDP from 20 to $26 \mathrm{~mm} \mathrm{Hg}$ (and a decrease in the aortic valve gradient from 56 to $14 \mathrm{~mm} \mathrm{Hg}$ ), which persisted at follow-up cardiac catheterization 2.5 years later. This patient had a Ross procedure for moderately severe aortic regurgitation 4 years after balloon valvuloplasty and has done well.

Five patients have not undergone a follow-up cardiac catheterization but have undergone a 2-D echocardiogram and Doppler study $0.5-3$ years (1.4 \pm 0.4 years) after valvuloplasty. In these patients, the peak instantaneous pressure gradient was $62 \pm 7 \mathrm{~mm} \mathrm{Hg}$ at follow-up, compared to $64 \pm 7 \mathrm{~mm} \mathrm{Hg}(P=0.19)$ immediately after valvuloplasty, and the degree of aortic insufficiency was unchanged from that immediately post-valvuloplasty.

All patients have done well clinically. Two patients had syncopal episodes prior to balloon valvuloplasty, which have resolved since the procedure. No patients have complained of exercise intolerance, chest pain, dizziness, or lower-extremity claudication.

\section{Comparison to Results in Children $<16$ Years of Age}

During the same 8-year period, 70 children under 16 years of age ( $6 \pm 0.7$ years) underwent aortic balloon

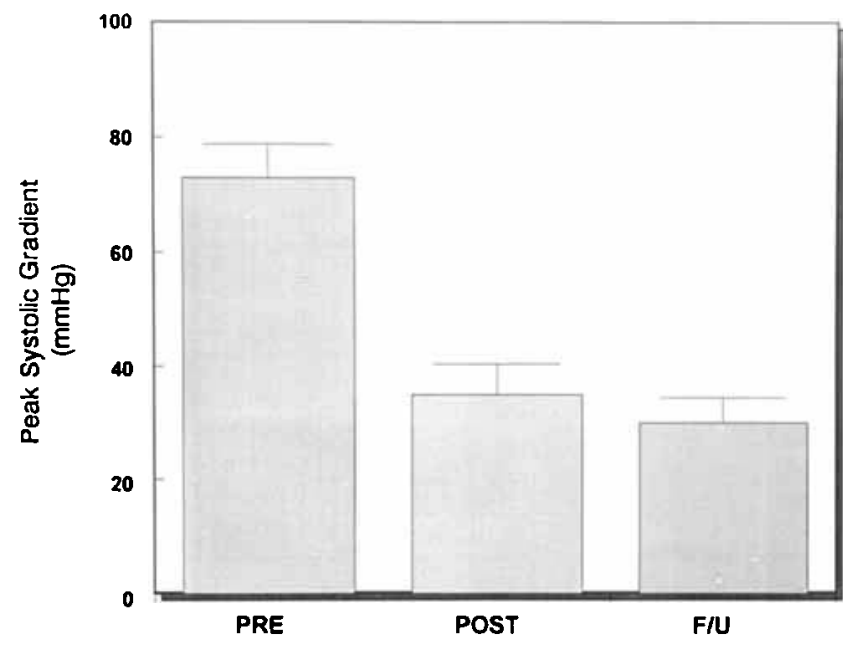

Fig. 3. Peak systolic aortic valve gradient before and immediately after valvuloplasty, and at follow-up 1.2-2.5 years (mean $\pm S E M, 1.5 \pm 0.1$ years) later.

valvuloplasty for congenital aortic stenosis at our institution. The effectiveness of balloon valvuloplasty in the young adults reported above compares favorably to the results in these younger children (Table II). Prior to balloon valvuloplasty, the peak systolic pressure gradient in the young adults was $73 \pm 5.8 \mathrm{~mm} \mathrm{Hg}$, compared to 79 $\pm 2.9 \mathrm{~mm} \mathrm{Hg}$ in the children $(P=0.31)$. Immediately after valvuloplasty, the gradient decreased to $35 \pm 5.4$ $\mathrm{mm} \mathrm{Hg}$ in the young adults, compared to $34 \pm 2 \mathrm{~mm} \mathrm{Hg}$ in the children $(P=0.67)$; at follow-up, the residual gradient was $30 \pm 4.4 \mathrm{~mm} \mathrm{Hg}$ in the young adults compared to $34 \pm 4 \mathrm{~mm} \mathrm{Hg}$ in the children $(P=0.44)$. There was also no difference in the degree of aortic insufficiency or cardiac index between the two groups immediately before and after valvuloplasty and at followup. The aortic valve annulus diameter in the young adults was $24 \pm 0.9 \mathrm{~mm}$ compared to $15 \pm 0.8 \mathrm{~mm}(P<0.001)$ in the children.

\section{DISCUSSION}

In the adult population, follow-up studies after percutaneous aortic balloon valvuloplasty have documented a high incidence of early restenosis and late mortality. Letac and Criber [11] for example describe a restenosis rate of $80 \%$ by 15 months of follow-up. In a recent editorial, Isom and Rosengart [3] stated "clinical applications of this approach (aortic balloon valvuloplasty) should be abandoned, except in the most unusual of circumstances. Open aortic valve replacement should remain the procedure of choice in almost every patient with critical aortic stenosis." These and other adult studies, however, have evaluated only elderly patients with acquired calcific aor- 
TABLE II. Comparison of Hemodynamic Data Between 15 Young Adults and 70 Chlldren Undergoing Balloon Valvuloplasty for Congenital Aortic Stenosis: 1985-1992*

\begin{tabular}{lccc}
\hline & Young adults & Children & $P$-value \\
\hline Number & 15 & 70 & - \\
Age (yr) & $18 \pm 0.6$ & $6 \pm 0.7$ & 0.001 \\
Annulus (mm) & $24 \pm 0.9$ & $15 \pm 0.8$ & 0.001 \\
Gradient (mm Hg) & & & \\
$\quad$ Pre & $73 \pm 5.8$ & $79 \pm 2.9$ & 0.307 \\
Post & $35 \pm 5.4$ & $34 \pm 2$ & 0.67 \\
$\quad$ f/u & $30 \pm 4.4$ & $34 \pm 4$ & 0.441 \\
LV systolic (mm Hg) & & & \\
Pre & $179 \pm 7.5$ & $171 \pm 4$ & 0.459 \\
Post & $147 \pm 6.5$ & $130 \pm 3$ & 0.09 \\
f/u & $147 \pm 4$ & $140 \pm 4$ & 0.369 \\
\hline
\end{tabular}

*Mean $\pm \mathrm{SE}$.

f/u. follow-up catheterization ( $1-3$ years after valvuloplasty); LV. left ventricular; Post, immediately after valvuloplasty: Pre, immediately before valvuloplasty.

tic stenosis $[1-4,10]$. It is unwarranted to apply these data to an adult population with congenital aortic stenosis, since the valvar substrate is different. Unlike the elderly, in whom aortic stenosis is caused by a degenerative calcium-laden valve, in the adult with congenital aortic stenosis fusion of the commissures is the primary anatomic problem. Previous studies have shown that balloon valvuloplasty can effectively relieve obstruction across a congenitally stenotic aortic valve by creating tears along the lines of commissural fusion. In an in vitro study of balloon dilatation of stenotic aortic valves Waller et al. [12] concluded that the mechanism of dilation in valves with commissural fusion was by commissural splitting.

The present study has demonstrated that the majority of young adults with congenital aortic stenosis have a beneficial response to percutaneous balloon valvuloplasty. Balloon valvuloplasty acutely reduced the peak systolic aortic valve gradient by $55 \%$ in these patients. Nine of the 15 patients had no immediate increase in aortic insufficiency, and only one had hemodynamically significant aortic regurgitation. The procedure provided inadequate relief of stenosis in only three patients. Follow-up cardiac catheterization studies $1.2-2.5$ years after valvuloplasty $(1.5 \pm 0.3$ years $)$ revealed no significant restenosis in the patients studied.

Previous studies in children with congenital aortic valve stenosis have documented excellent acute relief of stenosis after balloon valvuloplasty, without early restenosis [5-8]. Many centers have concluded that balloon valvuloplasty is now the treatment of choice for childhood aortic stenosis. The present study has found no statistical difference in the outcome of aortic balloon valvuloplasty in young adult patients compared to younger children treated concurrently. In both groups, the gradient relief, early and late, and the degree of aortic insufficiency produced by the procedure were similar. These findings suggest that balloon valvuloplasty should be considered the treatment of choice for young adults with congenital aortic stenosis, as it is for children.

\section{CONCLUSION}

Our acute and follow-up data indicate that percutaneous balloon valvuloplasty is effective in reducing the pressure gradient in most young adults with congenital aortic stenosis. The acute reduction in the peak systolic gradient of 55\% persisted at follow-up an average of 1.5 years, documenting good intermediate-term effectiveness. The results of this technique in these young adults appear to be as beneficial as those in younger children with congenital aortic stenosis, an age group in which balloon valvuloplasty has been widely accepted. From this small series, we are not able to determine the upper age limit for this recommendation, but we believe that valvuloplasty is likely to benefit patients with congenital aortic stenosis regardless of age, provided the valve annulus is not hypoplastic and the valve leaflets are not severely calcified.

\section{REFERENCES}

1. Bernard Y, Etievant J, Mourand JL, Anguenot T, Schiele F, Guseibat M, Bassand JP: Long-term results of percutaneous aortic valvuloplasty compared with aortic valve replacement in patients more than 75 years old. J Am Coll Cardiol 20:796-801, 1992.

2. Hostetler MD, Dunn MI: Percutaneous balloon aortic valvuloplasty: Dr. Bailey revisited. J Am Coll Cardiol 20:802-803, 1992.

3. Isom WO, Rosengart TK: Percutaneous aortic valvuloplasty: Off the Bandwagon, Again. J Am Coll Cardiol 20:804-805, 1992.

4. Diethrich $\mathbf{E}$. The treatment of aortic stenosis: Is valvuloplasty ever an alternative to surgery. J Intervent Cardiol 6:7-13, 1993.

5. O'Connor BK, Beekman RH, Rocchini AP, Rosenthal A: Intermediate-term effectiveness of balloon valvuloplasty for congenital aortic stenosis. A prospective follow-up study. J Am Coll Cardiol 84:732-738, 1991.

6. Meliones JM, Beekman RH, Rocchini AP, Lacina SJ: Balloon valvuloplasty for recurrent aortic stenosis after surgical valvotomy in childhood: Immediate and follow-up studies. J Am Coll Cardiol 13:1106-1110, 1989.

7. Witsenburg M, Cromme-Dijkhuis AH, Frohn-Mulder IME, Hess J: Short and mid-term results of balloon valvuloplasty for valvular aortic stenosis in children. Am J Cardiol 69:945-950, 1992.

8. Shaddy RE, Boucek MM, Sturtevant JE, Ruttenberg HD, Orsmond GS: Gradient reduction, AV regurgitation and prolapse after aortic valvuloplasty in 32 consecutive patients with congenital aortic stenosis. J Am Coll Cardiol 16:451-456. 1990.

9. Rocchini AP, Beekman RH, Shachar GB, Benson L, Schwartz D, Kan JS: Balloon aortic valvuloplasty: Results of the valvuloplasty and angioplasty of congenital anomalies registry. Am J Cardiol $65: 784-789,1990$ 
10. NHLBI Balloon valvuloplasty registry participants-Balloon aortic valvuloplasty. Circulation 84:2383-2397, 1991.

11. Letac B, Criber A: Aortic balloon dilatation as a treatment of aortic stenosis: What are the indications? J Intervent Cardiol 6:1-6, 1993.
12. Waller BF, McKay C, VanTassel JW, Taliercio C, Howard J, Green F: Catheter balloon valvuloplasty of stenotic aortic valves. Part I. Anatomic basis and mechanisms of balloon dilation. Clin Cardiol 14:836-846, 1991. 